\title{
Aging and Ageism
}

\section{Richard Ferraro*}

National Academy of Neuropsychology, Department of Psychology, University of North Dakota, USA

*Corresponding author: Richard Ferraro , Department of Psychology, University of North Dakota, Grand Forks, ND 58202-8380, Tel: 701-777-2414; E-mail: f.richard.ferraro@email.und.edu

Received date: June 15, 2016, Accepted date: June 16, 2016, Published date: June 23, 2016

Copyright: $(2016$ Ferraro R, et al. This is an open-access article distributed under the terms of the Creative Commons Attribution License, which permits unrestricted use, distribution, and reproduction in any medium, provided the original author and source are credited.

\section{Editorial}

Last year, I published a paper investigating ageism in US and Canadian samples, aged 40-72 years [1]. Results revealed two interesting (yet troubling) results. First, Ageism Survey scores increased as scores on the Geriatric Depression Scale-Short Form (GDS-SF) increased for both samples. That is, those experiencing an ageism event once or more than once reported greater GDS-SF scores. Second, this association was more pronounced in women as compared to men. In an era were individuals are living longer and more is known about diagnosing and dealing with many diseases associated with age (e.g., Alzheimer's disease), one wonders why the ravages of ageism are still present and still rampant in our society. The numbers of older adults older than 85 and older than 100 are rapidly on the rise, although ageism can occur at any age. A more critical question is what can be done to curb and reduce ageism?

Given what is known about the negative impact ageism has on older adults, several options for curbing ageism is possible. First, treat it like any other -ism such as racism or sexism. Confront it and deal with it. Identify types of ageism (subtle, not subtle) and educate individuals about what it is and what is does. Second, our society needs more individuals trained in aging and gerontology. Few mental and medical health professionals go into geriatrics or gerontology. That has to be reversed so that more can be known about aging and ageism and that more can be disseminated about aging and ageism. Third, all professional organizations (work, school, etc.) need to have plans in place for training and identification of all forms of ageism. Many types of ageism (like other - isms) are unconscious and automatic and below most individuals' awareness level and as such go unnoticed. Yet the after-effects are devastating. Making someone aware of their ageism may be an effort to reduce the ageism.

We live in a time in which great progress is being made about how we age, why we age and why some age better (or worse) than others. These are word-wide effects and progress on these fronts can only be achieved when individuals, societies and cultures tackle ageism headon in an attempt to reduce its impact.

\section{References}

1. Ferraro FR (2015) Ageism in US and Canadian samples. Int J Psychol Res 9: 1-7. 